\title{
TERCEIRO SETOR, ROTARY INTERNACIONAL E FUNDAÇÃO ROTÁRIA: DO VOLUNTARISMO AO IMPACTO GLOBAL NA EFETIVAÇÃ̃O DE DIREITOS
}

\author{
THIRD SECTOR, ROTARY INTERNATIONAL AND ROTARY FOUNDATION: FROM \\ VOLUNTEERISM TO THE GLOBAL IMPACT ON THE EFFECTIVENESS OF RIGHTS
}

Fernando Gustavo Knoerr

Pós-Doutor pela Universidade de Coimbra. Doutor, Mestre em Direito do Estado e Bacharel pela Universidade Federal do Paraná (UFPR). Professor do Programa de Mestrado em Direito Empresarial e Cidadania do Centro Universitário Curitiba (UNICURITIBA). Professor de Direito Administrativo da Escola da Magistratura do Paraná e da Fundação Escola do Ministério Público do Paraná. E-mail: fernando@sellosknoerr.com.br

Viviane Sellos Knoerr

Pós-Doutor pela Universidade de Coimbra. Doutora em Direito do Estado pela Pontifícia Universidade Católica de São Paulo. Mestre em Direito das Relações Sociais pela Pontifícia Universidade Católica de São Paulo. Graduada em Direito pela Universidade Federal do Espírito Santo. Advogada. Professora e Coordenadora do Programa de Mestrado em Direito Empresarial e Cidadania do Centro Universitário Curitiba (UNICURITIBA). E-mail: viviane@sellosknoerr.com.br

Leonardo Sanches Ferreira

Mestrando em Direito Empresarial e Cidadania do Centro Universitário Curitiba (UNICURITIBA). Bolsista Integral PROSUP-CAPES. Pesquisador Internacional na Universidade de Regina - Canadá. Membro dos Grupos de Pesquisa "Responsabilidade Social da Empresa no Século XXI" e "Tutela dos direitos da personalidade na atividade empresarial - os efeitos limitadores na constituição da prova judiciária”, junto ao CNPq. Advogado.

E-mail: sanchesf.leonardo@gmail.com

Recebido em: 30/08/2018

Aprovado em: 30/01/2019

RESUMO: O presente trabalho analisa o reflexo e a influência do Rotary Internacional e da Fundação Rotária, que integram o terceiro setor, quanto ao impacto global que produzem através de seus projetos e de que forma auxiliam na efetivação de direitos constitucionalmente previstos. Inicialmente realiza-se um estudo acerca da história do voluntarismo no mundo ocidental e no Brasil. Na sequência, busca-se a determinação do que constitui o terceiro setor, para, por fim, verificar como o Rotary Internacional e a Fundação Rotária promovem um impacto global pelas suas ações. Conclui-se que a atuação das instituições produz significativos resultados em matéria de efetivação de direitos. Para tanto, a pesquisa será pautada pelo método dedutivo de investigação, além da utilização de referencial bibliográfico atinente ao tema.

Palavras-chave: Rotary Internacional. Fundação Rotária. Voluntarismo. Impacto Global. Efetivação de Direitos.

ABSTRACT: This paper analyzes the impact and influence of Rotary International and The Rotary Foundation, which are part of the third sector, on the global impact they produce through their projects and how they help to achieve constitutional rights. Initially, a study is made of the history of voluntarism in the Western world and in Brazil. The next step is to determine what constitutes 
the third sector, to see how Rotary International and The Rotary Foundation have a global impact on their actions. It is concluded that the performance of institutions produces significant results in terms of effectiveness of rights. In order to do so, the research will be guided by the deductive method of investigation, in addition to the use of a bibliographic reference on the subject.

Keywords: Rotary International. The Rotary Foundation. Voluntarism. Global Impact; Realization of Rights.

SUMÁRIO: Introdução; 1 A Tragetória do Voluntariado; $1.1 \mathrm{O}$ Voluntarismo no Mundo; $1.2 \mathrm{O}$ Voluntarismo no Brasil; 2 A Identificação do Terceiro Setor; 2.1 A Busca por um Conceito; $2.2 \mathrm{O}$ Terceiro Setor no cenário nacional; 3.1 A tragetória do Rotary; 3.2 A Efetivação de Direitos pelo Rotary Internacional e pela Fundação Rotária;

\section{INTRODUÇÃO}

A concepção de que o Estado e o mercado são os principais personagens da sociedade capitalista globalizada há muito tempo é disseminada e possui justificativa quando analisado a partir de diversos acontecimentos históricos, econômicos e políticos. No entanto, existe um terceiro elemento nesta conjuntura que merece especial destaque: a sociedade organizada. Esta não se encontra revestida das prerrogativas típicas aos Estados soberanos, na busca pela satisfação das necessidades públicas; tampouco tem como objetivo primeiro a persecução do lucro, relacionada a iniciativa privada ao mercado livre.

A atuação da comunidade como uma organização coletiva pode ser verificada em inúmeros acontecimentos históricos e seus resultados, por vezes, foram determinantes no desenvolvimento tanto do Estado quanto do mercado. Trata-se de um poder que durante muito tempo não foi visualizado, sequer transposto a objeto de estudo científico.

A este seguimento da sociedade que tem suas ações direcionadas às necessidades comuns e à tutela dos necessitados foi denominado Terceiro Setor. Este termo vem sendo cunhado desde a década de 1970 nos Estados Unidos da América e vem ganhando cada vez mais espaço na realidade social e acadêmica. Destacam-se, dentre as diversas instituições que compõem o terceiro, o Rotary Internacional e a Fundação Rotária, concebidos e criados no estado norte-americano e que possuem atividades de alcance em quase todos os países do mundo.

Desta forma, a presente pesquisa tem como objetivo analisar o reflexo e a influência do Rotary Internacional e da Fundação Rotária, quanto ao impacto global que produzem através de seus projetos e de que forma auxiliam na efetivação de direitos constitucionalmente previstos. Para tanto, a pesquisa será realizada em três tópicos. Inicialmente realiza-se uma reconstrução da trajetória do voluntarismo no mundo ocidental e de seus impactos na sociedade. A pesquisa se dá em âmbito internacional e nacional.

Na sequência, verifica-se como ocorreu o processo de identificação do terceiro setor enquanto segmento próprio de atuação e como a construção deste conceito ainda passa por modificações. Complementarmente, a legislação nacional que trata sobre o tema é apresentada. Ao final, o estudo sobre o Rotary Internacional e a Fundação Rotária é utilizado para demonstrar o poder da ação coordenada e conjunta da sociedade na promoção e efetivação de direitos que, por vezes, não são atendidos e prestados pelo Estado ou pelo mercado.

Utiliza-se do método dedutivo de investigação, com pesquisa bibliográfica sobre as produções existentes sobre a presente temática. Destaca-se que o tema do terceiro setor é analisado por diversas das ciências sociais, o que permite o diálogo do direito com outros ramos do saber. 


\section{A TRAGETÓRIA DO VOLUNTARIADO}

A história da sociedade demonstra que o voluntariado sempre esteve presente entre as relações humanas, ainda que não da forma como hoje é apresentado. Estudar o voluntarismo significa debruçar-se sobre as formas como o homem em comunidade encontrou para auxiliar e prestar apoio aos necessitados. Neste sentido, "a esmola, a exortação e a persuasão como recursos elementares caracterizam este largo período de origem do voluntariado, no qual a fé, o sentimento e a intuição substituem o conhecimento científico frente às situações que geram tal estado de carência” (KISNERMAN, 1983, p. 3).

Mike Hudson (1999, p. 01) pontua que o voluntarismo pode ser verificado em períodos remotos da história, como na antiga sociedade grega, em que viajantes recebiam comida e abrigo na casa dos ricos ou eram recebidos por camponeses. Outro exemplo é visível na atuação dos profetas judeus, que trabalhavam em prol da justiça social, da política e da economia. Os romanos, por sua vez, defendiam que "os cidadãos notáveis, os bem nascidos, também devem alimentar sua cidade", sendo que o fato de aliviar alguma aflição dos pobres consistia em "beneficiar o corpo cívico no conjunto" (VEYNE, 1990, p. 251).

Fica claro, desta maneira, que o voluntarismo, ainda que não assim intitulado, está presente na vida em sociedade e seu papel de relevância constitui objeto de estudo do presente trabalho. Analisa-se, na sequência, a evolução do voluntarismo tanto no mundo ocidental, em geral, quanto sua experiência no Brasil.

\subsection{O Voluntarismo no Mundo}

A igreja assumiu posição determinante no desenvolvimento da sociedade, do Estado e do direito. Não se deu de maneira diferente no que tange ao voluntarismo. Inúmeros são os autores que pontuam o papel central da igreja no crescimento e manutenção da atividade social voltada à proteção dos menos favorecidos. Tal afirmação é verificada na obra de Mike Hudson (1999, p. 02), quando afirma que "as primeiras igrejas cristãs criaram fundos para apoio às viúvas, órfãos, enfermos, pobres, deficientes e prisioneiros. Esperava-se que os fiéis levassem donativos, voluntariamente, que eram colocados na mesa do Senhor". Kisnerman (1983) assevera que dois autores são vistos como marcos na construção do voluntarismo enquanto objeto de pesquisa científica, sendo eles Juan Luis Vives e Vicente de Paulo.

O primeiro, Juan Luis Vives, autor da obra "Da assistência aos pobres" escrita em 1526, realizou uma pesquisa de casa em casa em Bruxelas, na Bélgica, com objetivo de listar as necessidades e as causas de miséria. Ele afirmou que a assistência aos indivíduos constituía um ato do bom cristão. Este modelo de pesquisa foi implementado em outros locais ao longo do século XVI, como em Londres e em Norwich (HUDSON, 1999, p. 03).

O segundo, Vicente de Paulo, que era fruto da igreja católica, também no século XVI, organizou a entidade "Damas da Caridade" composta por mulheres de famílias aristocratas, que se dedicavam a visitar doentes e pobres para proporcionar ajuda. No entanto, conforme adverte Kisnerman (1983, p. 5), o grupo não prosperou em razão de oposição criada pela própria igreja católica, que defendia ser papel das mulheres o cuidado de sua casa e de sua família, não de terceiros. Ocorre que tal negativa não foi suficiente para interromper os trabalhos desenvolvidos por Vicente de Paulo. Ele passou a recrutar jovens de famílias de camponeses, que inicialmente foram reconhecidas como "Servas dos Pobres", depois como "Filhas de Caridade" e, por fim, "Irmãs de Caridade". O legado de Vicente de Paulo foi perpetuado no século XIX por Frederico Ozanan que organizou as Conferências de São Vicente de Paulo, na França. 
Destaca-se que o trabalho em prol do voluntariado não foi realizado apenas pela igreja católica. Kisnerman (1983, p. 5-6) postula que a atuação do protestantismo também foi determinante, sendo que os pastores protestantes advertiram pela necessidade de estudo acerca das mazelas sociais, com principal enfoque na prevenção e na reabilitação. Em 1765, os protestantes criaram o chamado Sistema de Hamburgo, voltado à assistência dos pobres. Torna clara a diferença na forma de atuação das igrejas: "a ação da igreja católica, baseada na caridade e orientada para ações individuais, contrasta com a do Protestantismo, baseada na filantropia, quer dizer, na boa vontade com os semelhantes, na fraternidade humana".

Hudson (1999, p. 03), de forma complementar, elenca ainda uma organização de suma relevância neste período, a Charity Organization Society (Sociedade para a Organização da Caridade), surgida na Inglaterra no ano de 1869. A organização teve como inspiração o trabalho acadêmico desenvolvido por Henry Solly, intitulado "Society of Arts". Tanto a pesquisa quanto o grupo tinham como objetivo evitar a continuidade na prestação de ajuda indiscriminada aos indigentes, o que favorecia sua permanência em estado de miséria. O lema da organização era "esmolas não, mas um amigo sim". A atuação do grupo foi efetiva, resultando na criação da COS também nos Estados Unidos da América, no ano de 1970. Ressalta-se que no ano de 1931, Jane Addams, ativista norte-americana da COS, recebeu o Prêmio Nobel da Paz em razão dos projetos realizados junto à organização.

\subsection{O Voluntarismo no Brasil}

A história do voluntarismo no Brasil assemelha-se com a do próprio Estado, no que diz respeito à ligação umbilical com a igreja católica. O primeiro marco reconhecido se deu na década de 1540, quando foi fundada a Santa Casa da Misericórdia, na Vila de Santos, na antiga capitania de São Vicente. A assistência voltada aos necessitados se dava de maneira conjunta entre as câmaras municipais e as Casas de Misericórdia, sendo que sua atuação "apoiava-se em um modelo importado pelas Casas de Misericórdia portuguesas, de iniciativas caritativas e cristãs, que tratavam da questão social como de resolução da sociedade, mediante a criação de asilos, educandários e corporações profissionais" (CABRAL, 2007, p. 56).

Pela adoção deste modelo, a atuação livre da sociedade em prol dos necessitados encontravam entraves significativos. "Fazer a história de organizações civil, do tipo associativo e voluntário, com autonomia do Estado e da Igreja, durante a maior parte da construção da sociedade brasileira, é como procurar agulha em palheiro" (LANDIM; CARVALHO, 2007, p. 6).

Faleiros leciona que "na primeira década do século XVIII houve um agravamento das tensões entre o governo colonial e as Misericórdias, referente às despesas e financiamento da assistência a crianças expostas, como também à assistência hospitalar prestada por estas a presos e soldados" (1995, p. 228). Desta forma, a atuação voluntária no Brasil encontrava barreiras orçamentárias, o que dificultavam sua efetivação.

É somente no século XX, conforme lição de Pilotti e Rizzini (1995, p. 38), que a atuação do voluntariado ganha relevância em favor da infância, dado o movimento médico higienista e pela demanda crescente da construção de uma rede profissionalizante de ensino. Peliano (2001, p. 20) destaca que os anos 1990 foram decisivos para a atuação voluntária no cenário nacional pela confluência dos seguintes fatores: abertura da economia, privatização de empresas estatais, crise política e econômica, fortalecimento da sociedade civil, maior envolvimento das ONGs e busca de melhoria na qualidade dos processos de gestão das empresas nacionais.

Dentre os principais projetos voltados ao voluntarismo podem ser destacadas a chegada da Cruz Vermelha ao Brasil, no ano de 1908; e o estabelecimento do escotismo para ajudar o 
próximo, em 1910. Já na segunda metade do século XX, a criação da APAE, em 1961, impactou significativamente a assistência aos portadores de deficiência mental. Pode-se afirmar que as alterações iniciados no século XX resultam no que hoje entende-se como terceiro setor, motivo pelo qual serão analisadas em tópico próprio.

Por fim, cabe chamar atenção para as distinções existentes entre os principais personagens no desenvolvimento do voluntariado no Europa, nos Estados Unidos e na América Latina. Nos estados europeus, a assistência aos necessitados possuía amparo na legislação social determinada pelo Estado; no estado norte-americano a tutela dos pobres era coordenada pela iniciativa privada; enquanto na América Latina, conforme advertência de Kisnerman (1983, p. 10) "seria o Estado intervencionista, com a colaboração de instituições religiosas católicas, que passaria a sustenta-las por meio das chamadas instituições de bem-estar social”.

Vê-se que o processo de desenvolvimento do voluntarismo deu-se de maneira diferenciada em cada um dos centros analisados, o que, certamente, contribui para que seus processos de institucionalização em terceiro setor também ocorra de formas distintas.

\section{A IDENTIFICAÇÃO DO TERCEIRO SETOR}

A atividade voluntária, como anteriormente mencionado e demonstrado, acompanha o desenvolvimento da sociedade e pode ser identificada nos mais distintos contextos e realidades. No entanto, estudar o Terceiro Setor como objeto de investigação científica apresenta-se como algo novo. Significa dizer que "a expressão surgiu há pouco mais de duas décadas e seu uso mais generalizado se deu há menos de cinco anos", "mas o fato a que se refere não o é em absoluto. Não se trata de um setor novo, mas de algo que tem raízes tão antigas quanto à presença portuguesa na América" (FALCONER; VILELA, 2001, p. 27).

A incapacidade do Estado, por si só, em atender todas as demandas sociais, econômicas e políticas é essencial para a compreensão do papel assumido pelo terceiro setor no cenário nacional e mundial. Desta forma, o objetivo da academia é determinar como um acontecimento que acompanha a história da própria sociedade pode ser visto através de uma nova ótica: uma esfera específica, denominada Terceiro Setor.

\subsection{A Busca por um Conceito}

A construção doutrinária acerca do terceiro setor encontra-se em constante movimento, tendo em vista que seu objeto de análise está em continuo processo de evolução e aprimoramento. No entanto, a academia apresenta controvérsias quanto ao significado do termo tanto em âmbito nacional como internacional. Teodósio (2002, p. 14) afirma que "grande parte da literatura destaca e/ou constata que o grau de informação e conhecimento sistematizado sobre o Terceiro Setor ainda é insipiente".

Bombal (2001, p. 03) adverte que o terceiro setor enquanto objeto de investigação possui "caractér fertemente multi-disciplinário. A sus análisis concurren investigadores que provienen de la sociología, la economía, las ciencias políticas, la antropología, pero también son importantes las disciplinas ligadas a la administración y gestión de las organizaciones". Acrescenta-se, ainda, o estudo jurídico acerca do tema, dada a produção legislativa existente e seu impacto na efetivação de direitos legalmente previstos.

O primeiro setor é representado pelo Estado, que cuida das necessidades públicas e do interesse público; o segundo setor é constituído pelo mercado e pela iniciativa privada; e, por fim, o terceiro setor é composto pela sociedade civil, que defende interesses comuns. Hudson (1999, p. 
11) define o terceiro setor como "organizações cujos objetivos principais são sociais, em vez de econômicos. A essência do setor engloba instituições de caridade, organizações religiosas, entidades voltadas para as artes, organizações comunitárias, sindicatos, associações profissionais, e outras organizações voluntárias".

O termo terceiro setor começou a ser utilizado nos Estados Unidos da América, nos anos 1970, para designar o setor da sociedade que atuava em organizações sem finalidades lucrativas. Em 1972, Amitai Etzioni publicou na Revista Business and Society Review o artigo intitulado "The Untapped Potential of the 'Third Sector',', no qual defendia a mudança de orientação na política social do governo de Nixon, pelo incentivo a criação e fomento de organizações privadas sem fins lucrativos (ETZIONI, 1972, p. 34).

Contudo, a adoção majoritária pelo termo "terceiro setor" deve-se aos estudos desenvolvidos por Lester Salamon, do Johns Hopkins Comparative Nonprofit Project, no final dos anos 1980. Nas palavras de Salamon e Anheier (1997, p. 11), seus estudos visavam "preencher as lacunas do conhecimento já antigo sobre as milhares de escolas, hospitais, clínicas, organizações comunitárias, grupos de pressão, centros de atendimento, organizações humanitárias (...) e outras que constituem esse importante setor".

Salamon (1994, p. 10-22) afirma que quatro crises e duas mudanças revolucionárias foram determinantes para a retração do papel do Estado e para o crescimento do caráter associativo: a crise do Walfare State moderno; a crise do desenvolvimento do Terceiro Mundo; a crise do meio ambiente global; a crise do socialismo; a revolução das comunicações; e o crescimento mundial dos anos 1960. Ao resultado destes acontecimentos, Salamon denominou "Revolução Associativa", período no qual intensificou-se a participação de organizações não lucrativas na busca pela efetivação de direitos.

Seguindo a doutrina de Salamon e Anheier (1992, p. 125-151), o terceiro setor é constituído por organizações que apresentem em maior ou menor grau as seguintes características: formalização; natureza privada; não distribuição de lucros; autogestão; e participação voluntária. Este conceito apresentado pelos autores é o que possui maior adesão pela academia, sendo utilizada para a verificação dos efeitos do terceiro setor em diversos países do globo.

\subsection{O Terceiro Setor no cenário nacional}

A identificação do terceiro setor no Brasil, ainda somente como realidade social e não acadêmica, remota o início do século XX. No ano de 1916 entrou em vigência a Lei $n^{\circ} 3.071$, de $1^{\circ}$ de janeiro de 1916, que instituiu o Código Civil e previu a possibilidade de existência jurídica de associações, fundações e sociedades civis sem fins econômicos. Foi um passo significativo na construção jurídica acerca do terceiro setor e dos moldes que até hoje são implementados.

Outro fator de suma relevância foi a urbanização e a industrialização ocorridas nas décadas de 1920 e 1930, culminando em novas organizações sociais nos espaços urbanos. De acordo com o relatório do BNDES (2001, p. 7), neste período várias entidades da sociedade civil passaram a se formar, muitas das quais atreladas ao Estado, como os sindicados, as federações e as confederações. "No campo institucional, com a Constituição de 1934, o Estado brasileiro assumiu o modelo de Estado social, passando a voltar sua atenção também para a área econômica e social" (MÂNICA, 2007, p. 176), direcionando aporte de recursos para organizações assistenciais. Ocorre que, para tanto, exigia prestação de contas, o que evidencia a interferência do Estado.

Ainda na década de 1930, a Lei $\mathrm{n}^{\circ}$ 91, de 28 de agosto de 1935, instituiu o título de

Utilidade Pública Federal, concedido às organizações que serviam desinteressadamente à sociedade. No entanto, apresentava em seu artigo $4^{\circ}$ que "as sociedades, associações e fundações 
declaradas de utilidade pública ficam obrigadas a apresentar todo os anos, (...) relação circunstanciada dos serviços que houverem prestado à coletividade", evidenciando a forte vinculação com o Estado.

Ao final da década de 1950, entrou em vigência a Lei no 3.577 , de 4 de julho 1959, que "isenta da taxa de contribuição de previdência dos Institutos e Caixas de Aposentadoria e Pensões as entidades de fins filantrópicos reconhecidas de utilidade pública, cujos membros de suas diretorias não percebem remuneração".

Já na década de 1970, as organizações não-governamentais - ONGs, "surgidas no âmago da resistência política, tiveram um papel fundamental nos rumos da sociedade brasileira e na consolidação do terceiro setor" (SILVA, 2010, p. 1309). Foram as responsáveis pela entrada de recursos de organizações internacionais no fomento das atividades do setor. Ademais, na década de 1980, tendo como acontecimentos históricos a queda da ditatura, a consolidação democrática e as dificuldades socioeconômicas, a atuação das organizações não-governamentais se deu de forma mais ampla (SILVA, 2010, p. 1310).

Com a promulgação da Constituição Federal da República Federativa do Brasil em 1988, o terceiro setor ganha ainda mais destaque pela desburocratização promovida e pelo amplo apoio constitucional. Em termos de legislação, foram ainda editadas: a Lei $\mathrm{n}^{\circ}$ 9.608, de 18 de fevereiro de 1998, que apresenta a disciplina jurídica do serviço voluntário; a Lei no 9.637, de 15 de maio de 1996, que dispõe sobre a qualificação de entidades como organizações sociais, pessoas jurídicas de direito privado, sem fins lucrativos, cujas atividades sejam dirigidas ao ensino, à pesquisa científica, ao desenvolvimento tecnológico, à proteção e preservação do meio ambiente, à cultura e à saúde; a Lei no 9.790, de 23 de março de 1999, que dispõe sobre a qualificação de pessoas jurídicas de direito privado, sem fins lucrativos, como Organizações da Sociedade Civil de Interesse Público - Oscips, complementada pelo Decreto no 3.100, de 30 de junho de 1999. A Lei $n^{\circ}$ 9.790/1999 inovou no que diz respeito à remuneração de seus dirigente, ao prever tal possibilidade em seu artigo $4^{\circ}$, inciso VI.

Por fim, a Lei $\mathrm{n}^{\mathrm{o}}$ 10.406, de 10 de janeiro de 2002, institui o Código Civil vigente e promoveu significativo mudança legislativa em matéria de terceiro setor. Prevê entre seus artigo 53 a 69, a possibilidade de existência jurídica de associações e fundações, excluindo as sociedades civis sem fins lucrativos. Consigna que "constituem-se as associações pela união de pessoas que se organizem para fins não econômicos" e que "para criar uma fundação, o seu instituidor fará, por escritura pública ou testamento, dotação especial de bens livres, especificando o fim a que se destina, e declarando, se quiser, a maneira de administrá-la".

Cabe, ainda, destacar o conceito dado pelo BNDES, que leciona que "o terceiro setor constitui-se na "esfera de atuação pública, não-estatal, formada a partir de iniciativas privadas voluntárias, sem fins lucrativos, no sentido do bem comum" (2001, p. 4).

No tocante ao desenvolvimento acadêmico do terceiro setor, dois autores ganham destaque na introdução do tema nas pesquisas brasileiras: Leilah Landim e Rubem César Fernandes. A primeira é autora da obra intitulada "Para além do Mercado e do Estado", de 1993; o segundo é autor do livro "Privado porém público: o terceiro setor na América Latina", de 1994.

Landim teve como objetivo fazer um apanhado histórico do desenvolvimento do terceiro setor no Brasil. "Além da evolução histórica, neste trabalho Landim fez um levantamento sobre a questão legal do universo sem fins lucrativos no Brasil, bem como um primeiro levantamento junto à Receita Federal sobre o perfil das organizações" (ALVES, 2002, p. 11). A obra de Fernandes, por sua vez, "trata-se antes de uma profissão de fé do que um livro com todos os rigores que o campo acadêmico exige. Mas, paradoxalmente, é uma das obras mais citadas nos meios acadêmicos brasileiros - sobretudo na área da Administração" (ALVES, 2002, p. 12). 
O terceiro setor ainda se apresenta como um desafio a ser estudado pelo direito e pelas demais áreas das ciências sociais. Seu conteúdo ainda é indefinido e a legislação atinente ao tema não alberga todos os sujeitos enquadrados nesta moldura jurídica. No entanto, é inquestionável a importância exercida pelo terceiro setor na sociedade atual e vários são os exemplos de organizações que promovem a efetivação de direitos em âmbito local, regional, nacional e, até mesmo, global.

\section{ROTARY INTERNACIONAL E FUNDAÇÃO ROTÁRIA: IMPACTO GLOBAL}

O Rotary Internacional é uma associação de clubes de prestação de serviços voluntários voltados à realização de serviços humanitários, a promoção de valore éticos e a criação da paz mundial. O responsável por sua fundação foi advogado Paul Francis Harris, que tinha como objetivo inicial reavivar o espírito de amizade e promover o bem para a sociedade.

A partir desta ideia, o advogado convidou três clientes de profissões distintas para uma reunião: Silvester Schiele, comerciante de carvão; Gustavus Loehr, engenheiro de minas; e Hiram Shorey, dono de uma alfaiataria. O encontro ocorreu na cidade de Chicago, nos Estados Unidos, no dia 23 de fevereiro de 1905. Ao final do mesmo ano, o primeiro Rotary Clube já possuía 30 associados. A nomenclatura Rotary é decorrente da forma como as reuniões ocorriam: rotativas entre os escritórios dos membros; e o lema é "seja a inspiração". O primeiro projeto comunitário desenvolvido pelo Rotary Clube de Chicago se deu no ano de 1907, pela instalação do primeiro sanitário público da cidade de Chicago, localizado próximo à prefeitura (ROTARY).

A partir deste iniciou-se um processo em cadeia de promoção da amizade e do bem comum, que tomou dimensões muito maiores do que as imaginadas por seus criadores.

\subsection{A tragetória do Rotary}

Três anos após a primeira reunião em Chicago foi criado o segundo clube rotário na cidade de São Francisco, na Califórnia. No ano seguinte, em 1909, outros quatro clubes foram criados em solo norte-americano. Este movimento inspirou a criação de novos clubes, até que no ano de 1910 foi realizada a primeira convenção do Rotary, em Chicago, congregando 16 clubes e Paul Harris foi eleito como primeiro presidente da Associação Nacional de Rotary Clubes.

Entre os anos de 1911 e 1913 são criados clubes no Canadá, na Inglaterra e na Irlanda, o que fez com que o nome da organização fosse alterado, passando a ser Associação Internacional de Rotary Clubes. No ano de 1916 é fundado o primeiro clube em país de idioma não inglês, em Havana, Cuba.

Em 1917, o presidente internacional Arch Klumph propôs a criação de um fundo de dotação para "fazer o bem no mundo". Sua ideia foi ouvida pelo Rotary Club de Kansas City, nos Estados Unidos, que realizou a doação US\$26,50 (vinte e seis dólares e cinquenta centavos) ao fundo sugerido pelo presidente. Esta iniciativa resultou na criação da Fundação Rotária no ano de 1918.

A história do Rotary no Brasil inicia-se na década de 1920, quando em 29 de janeiro um grupo predominante de negociantes estrangeiros, sediados na cidade do Rio de Janeiro, solicitaram a filiação ao Rotary Internacional. Ocorre que tal pedido não foi concedido, vez que a diretoria internacional entendeu que um clube localizado no Brasil deveria ser composto majoritariamente por brasileiros (ROTARY CLUB RJ).

Somente em 15 de dezembro de 1922, com apoio de Heriberto Percival Coates, então membro do Rotary Club de Montevidéu e representante do Rotary Internacional, foi fundado o 
primeiro clube rotário de língua portuguesa. De forma contínua, em 1924 foi fundado o Rotary Club de São Paulo, em 1927 os Rotary Clubs de Santos e Belo Horizonte, e em 1928 de Juiz de Fora e de Niterói.

Antes mesmo de completar seu aniversário de vinte anos, a instituição já contava com quase duzentos clubes e mais de vinte mil sócios em diversos países do mundo. No ano de 1945, quarenta e nove rotarianos, que compuseram a maior organização não-governamental presente na Fundação das Nações Unidas, colaboram na redação de sua carta de fundação. Além disso, no ano de 1943, o Rotary financiou uma conferência em Londres, que serviu como inspiração para a criação da Organização para a Educação, Ciência e Cultura (UNESCO), estabelecida pela ONU em 1946.

Com o falecimento do fundador do Rotary, Paul Harris, em 1947, a Fundação Rotária recebeu contribuições no valor de US\$1.300.000,00 (um milhão e trezentos mil dólares) em sua homenagem, o que tornou possível a concretização da visão de Arch Klumph, e a primeira turma de dezoito bolsistas do Rotary partiu para estudar no exterior, atuando como embaixadores da boa vontade ao representar os seus países de origem (ROTARY).

Atualmente, o quadro rotário é composto por 35.732 clubes no mundo, 1.208.229 de rotarianos, espalhados em 217 países e regiões (ROTARY). Trata-se de uma instituição de alcance global, com projetos que alteram a vida de milhões de pessoas. Em âmbito nacional, são 2.403 clubes, com 53.669 membros em todos os estados da federação.

No ano de 1979, a Fundação Rotária outorga subsídio para imunizar seis milhões de crianças contra a poliomielite nas Filipinas, o que deu início ao Programa Pólio Plus. Em 1985, o Rotary aprova de forma global o referido programa e consegue captar US\$120.000.000,00 (cento e vinte milhões de dólares) para a imunização de crianças pelo mundo todo. Três anos depois, em 1988, a campanha alcança o valor de US\$247.000.000,00 (duzentos e quarenta e sete milhões de dólares).

Em 1994, é atestada a eliminação da poliomielite do hemisfério ocidental, em 2000, a região do pacífico ocidental declara estar livre da doença, e em 2002 o mesmo acontece com a Europa. Desta forma, no ano de 2006, apenas quatro países no mundo ainda apresentavam a existência do vírus: Afeganistão, Índia, Nigéria e Paquistão (ROTARY). Em apoio a este projeto, entre os anos de 2007 e 2009, a Fundação Gates realizou uma doação no aporte de US\$355.000.000,00 (trezentos e cinquenta e cinco milhões de dólares).

Cumpre destacar que, ainda no ano de 1999, são estabelecidos os Centros Rotary de Estudos Internacionais na área de paz e resolução de conflitos, com objetivo de edificação da paz mundial.

\subsection{A Efetivação de Direitos pelo Rotary Internacional e pela Fundação Rotária}

A atuação da instituição rotária, como um todo, alterou e continua alterando a realidade de milhões de pessoas ao redor do globo. Desta forma, cabe analisar quais direitos previstos no ordenamento jurídico brasileiro são efetivados através das ações desenvolvidas pelo Rotary Internacional e pela Fundação Rotária. Elenca-se o direito à saúde; o direito à proteção da maternidade e da infância; o direito à educação; o direito ao desenvolvimento econômico e a criação de uma cidadania global voltada à paz mundial.

A Constituição Federal da República Federativa do Brasil de 1988 prevê em seu Preâmbulo que o Estado Democrático é "destinado a assegurar o exercício dos direitos sociais e individuais, a liberdade, a segurança, o bem-estar, o desenvolvimento, a igualdade e a justiça como valores supremos de uma sociedade fraterna, pluralista e sem preconceitos". Estabelece, ainda, em 
seu artigo $6^{\circ}$, que são direitos sociais a educação, a saúde, a proteção à maternidade e à infância, dentre outros.

Conforme já mencionado o Programa Pólio Plus é um forte instrumento de promoção e valorização da saúde. Com resultados concretos espalhados por todo o globo o projeto concretizou, também no Brasil, o direito à saúde ao evitar a proliferação do vírus da poliomielite. No tocante ao direito à proteção da maternidade e da infância, a instituição rotária promove "educação, vacinas, kits para partos e clínicas móveis. Ensinam mulheres a evitarem a transmissão do vírus HIV para seus bebês, amamentarem e protegerem a si e a seus filhos de doenças" (ROTARY).

Com relação do direito à educação, a Fundação Rotária apoia o ensino por meio de bolsas de estudo, doações e projetos em todo o mundo. Cita-se a título de exemplo: no Afeganistão, rotarianos abriram uma escola para meninas a fim de interromper o ciclo de pobreza e a desigualdade social; na África, rotarianos forneceram eletricidade e computadores, e deram treinamento básico aos professores para usarem a internet e outros recursos on-line a fim de obter materiais de ensino; rotarianos estão fornecendo água limpa a todas as escolas do Líbano para que os estudantes possam ter mais saúde e, consequentemente, melhor desempenho (ROTARY).

No que tange ao desenvolvimento econômico, diversas são as frentes de atuação do Rotary. As pessoas que os rotarianos treinam se tornam recursos para suas comunidades, oferecendo atividades de networking, aconselhamento sobre desenvolvimento de negócios, e treinamento sobre matemática e finanças.

Por fim, porém não menos importante, a atuação rotária volta-se aos objetivos traçados pelo texto constitucional na construção de uma sociedade livre, justa e solidária, ao passo que por meio de iniciativas humanitárias, bolsas de estudo e dos Centros Rotary pela Paz, os associados entram em ação para abordar as causas dos conflitos, como pobreza, desigualdade, tensões entres grupos étnicos, falta de acesso à educação e escassez de recursos. São iniciativas que possuem como finalidade a criação de uma cidadania global voltada à paz mundial. Verifica-se, assim, o quão efetiva pode ser a atuação do terceiro setor na promoção de direitos e de garantias.

\section{CONCLUSÃO}

A tomada de consciência por parte da sociedade é fundamental para que o direito escrito passe a ser o direito vivido. Significa dizer que quando a comunidade toma posse do poder que lhe é devido e chama para si a responsabilidade sobre determinados assuntos, é capaz de promover mudanças que o Estado levaria muito tempo para efetivar e busca soluções para questões que o mercado, por vezes propositadamente, não enxerga.

A atuação do Rotary Internacional e da Fundação Rotária corrobora com esta afirmação e evidencia como a vontade de fazer o bem pode, de fato, fazê-lo. A iniciativa de um pequeno grupo de amigos resultou no que hoje é uma das maiores organizações do mundo, com membros nos países menos acessíveis do globo.

O terceiro setor, enquanto resultado da atividade social, passa a integrar e ser reconhecido no ordenamento jurídico, ao passo que o legislador se vê na necessidade de regulamentar um segmento da sociedade que se mostra efetivo na concretização de direitos e na implementação de políticas que possuem caráter eminentemente público.

A experiência criada pelo Rotary Internacional e pela Fundação Rotária mostrou ser bem sucedida, tanto no impacto local quanto no alcance global de suas ações. Configura um exemplo real do poder detido pelo povo que, imbuído pela vontade de fazer o bem, edifica uma comunidade solidária e justa. 


\section{REFERÊNCIAS}

ALVES, Mário Aquino. Terceiro Setor: as origens do conceito. UFJF, 2002. Disponível em: http://www.ufff.br/virgilio_oliveira/files/2014/10/01-b-Alves-2002.pdf. Acesso em 13/08/2018.

BNDES. Terceiro setor e desenvolvimento setorial. Área de Desenvolvimento Social. Relato setorial $\mathrm{n}^{\circ}$ 03. Julho de 2001. Disponível em:

https://www.bndes.gov.br/SiteBNDES/export/sites/default/bndes_pt/Galerias/Arquivos/conhecim ento/relato/tsetor.pdf. Acesso em 13/08/2018.

BOMBAL, Inés Gonzalés. Producción, circulación y recepción de conocimientos sobre el tercer sector: nuevas preguntas. Anais Seminário “"Filantropía, Responsabilidad Social y Ciudadanía” CEDES- Fundación W.K.Kellogg. Antigua, Guatemala 3-5 Abril, 2001. Disponível em: http://www.lasociedadcivil.org/wp-content/uploads/2014/11/bombal.pdf. Acesso em 13/08/2018.

CABRAL, Eloisa Helena de Souza. Terceiro setor: gestão e controle social. São Paulo: Saraiva, 2007.

ETZIONI, Amitai. The Untapped Potential of the 'Third Sector'. In Business and Society Review. N. 1 Spring, 1972.

FALCONER, Andrés Pablo; VILELA, Roberto. Recursos privados para fins públicos: as grantmakers brasileiras. São Paulo: Peirópolis, 2001.

FALEIROS, Eva Teresinha Silveira. A criança e o adolescente: objetos sem valor no Brasil Colônia e no Império. In: A arte de governar crianças: a história das políticas sociais, da legislação e da assistência à infância no Brasil. Rio de Janeiro: Editora Universidade Santa Úrsula, 1995.

HUDSON, Mike. Administrando Organizações de Terceiro Setor. São Paulo: Makron Books, 1999.

KISNERMAN, Natálio. Introdução ao trabalho social. São Paulo: Editora Moraes, 1983.

LANDIM, Leilah; CARVALHO, Luiz Antônio de. Projeto transparência e prestação de contas da sociedade civil na América Latina - CASO: BRASIL. Uruguai: Instituto de Comunicação e Desenvolvimento (ICD), 2007. Disponível em: <www.rits.org.br>. Acesso em: 12/08/2018.

MÂNICA, Fernando Borges. Panorama histórico-legislativo do terceiro setor no Brasil. In: Terceiro Setor, empresas e Estado: novas fronteiras entre o público e o privado. Belo Horizonte: Fórum, 2007.

PELIANO, Ana Maria Medeiros. (Coordenadora) Bondade ou interesse? Como e por que as empresas atuam na área social. Brasília: IPEA, 2001. 
PILOTTI, Francisco de; RIZZINI, Irene. A arte de governar crianças: a história das políticas sociais, da legislação e da assistência à infância no Brasil. Rio de Janeiro: Editora Universidade Santa Úrsula, 1995.

ROTARY INTERNATIONAL. Sítio oficial. Disponível em: https://www.rotary.org/pt. Acesso em 14/08/2018.

SALAMON, Lester; ANHEIER, Helmut. Defining the nonprofit sector: a cross-national analisys. Manchester: Manchester University Press, 1997.

SALAMON, Lester; ANHEIER, Helmut. In search of the nonprofit sector I: the question of definitions. Voluntas, V. 3, N. 2, 1992. Disponível em:

https://www.scopus.com/record/display.uri?eid=2-s2.0-

0000147713\&origin $=$ inward\&txGid=5ac1974aa3e572a09d8a8e2928256ca8. Acesso em $13 / 08 / 2018$.

SALAMON, Lester; ANHEIER, Helmut. The rise of nonprofit sector. In Foreign Affairs. V. 73. N. 4, 1994.

TEODÓSIO, Armindo dos Santos de Souza. O terceiro setor como utopia modernizadora da provisão de políticas sociais: dilemas, armadilhas e perspectivas no cenário brasileiro. $120 \mathrm{f}$. Dissertação (Mestrado) - Pontifícia Universidade Católica de Minas Gerais, Belo Horizonte, 2002. Disponível em: https://www.researchgate.net/publication/305766238_O_TERCEIRO_SETOR_COMO_UTOPIA _MODERNIZADORA_DA_PROVISAO_DE_POLITICAS_SOCIAIS_DILEMAS_ARMADIL HAS_E_PERSPECTIVAS_NO_CENARIO_BRASILEIRO. Acesso em 13/08/2018.

VEYNE, Paulo. (Organizador) Do Império Romano ao ano mil - História da vida privada. São Paulo: Companhia das Letras, 1990. 